\title{
Impact of the global pandemic situation of COVID-19 on the growth of the economic level of private security services in the selected region
}

\author{
Martin Boros ${ }^{1, *}$, Andrej Velas ${ }^{1}$, Zuzana Zvakova $^{1}$, and Robert Mendel $^{1}$ \\ ${ }^{1}$ University of Zilina, Faculty of Security Engineering, Univerzitna 1, 01026 Zilina, Slovakia
}

\begin{abstract}
Research background: The research presented in the article is focused on assessing the impact of measures implemented against the spread of COVID-19 in the conditions of the Slovak Republic. We will focus primarily on curfews, work at home and the like, which are directly related to private security services and have affected the company's economic situation. An important factor influencing the economic level of society is also the ban on organizing sports events, at which private security services ensure the safety and protection of visitors, athletes and organizers.

Purpose of the article: The aim of the article is to determine the degree of impact of the pandemic situation caused by COVID-19 on the economic level and profitability of the mentioned companies in the selected Slovak region by means of a multi-year financial analysis of private security services.

Methods: The article will use several methods such as financial analysis, profitability analysis, comparison and other scientific methods such as forecasting the future situation in case they would take long-term antipandemic measures.

Findings \& Value added: The result of the research presented in the article will be an evaluation of the degree of impact on companies operating on the Slovak market in the field of security from the point of view of profitability due to the impossibility of performing employment. Among other things, the expected estimate of the time period that private security services can manage if they would last long-term compared to pandemic measures will be presented.
\end{abstract}

Keywords: impact rate; economic level; measures; COVID-19.

JEL Classification: $M 21 ; O 16 ;$ M42

\footnotetext{
* Corresponding author: martin.boros@uniza.sk
} 


\section{Introduction}

COVID - 19 has affected and is affecting the work and private lives of people around the world, travel and working conditions have been limited and have had a significant global impact on the economies of several countries. We are currently witnessing that due to the failure of chip production, production in the automotive industry is partially suspended.

In the fight against COVID-19, each country has taken its own measures to protect the lives of its inhabitants, even at the cost of reducing gross domestic product and the competitiveness of the state. Within the conditions of the Slovak Republic, it is possible to do business with several options, including a trade in which a person performs small activities. The second option is to own a company. In addition to the given differences, it is also possible to say the fact that in the case of a trade, a person is liable with all his property and in the case of a company only up to the amount of his deposit (Andrei, 2020) and Gruenbichler, 2021).

A separate group of business in Slovakia is security, where the Private Security Act directly defines the possibilities and forms of business, which is exceptional from the point of view of other industries (Private security act). According to Private Security Act, business in the field of security is possible in the form of a guard service, which is then divided into other subgroups aimed at protecting freely accessible or enclosed spaces, detective service, and other options (Boros, 2021). The second group is a technical service within which is meant all forms of technical security of the object such as camera systems, security systems and others (Bockelmann, 2019).

The COVID-19 pandemic has certainly also affected security business, as one of the activities of private security services is to provide protection at sporting events that have been banned as part of the prevention of the spread of COVID-19. It is therefore questionable to what extent these restrictions have affected the profitability of companies and whether they could be compared to the gastronomic industry that has suffered the most or to others that have not been greatly affected.

As business in the field of security is possible within the whole of Slovakia, we decided for our needs and the needs of the article to focus on selected companies within the Zilina region. The Zilina region is unique due to its diversity, as it contains sports clubs that play the highest sports Slovak leagues, production plants and many other important indicators.

\section{Methodology}

As mentioned in the previous chapter, we focused on the Zilina region and specifically on companies with comparable indicators. These indicators were the performance of the guard service, a separate category according to (Private Security Act), a comparable number of employees - medium-sized enterprises, according to (Buganova, 2018) and a market presence of at least ten years. As part of the market analysis, we finally evaluated five companies, out of a total of eighteen. Other companies were excluded due to noncompliance, mainly the size of the company.

After creating a list of companies, we proceeded to a financial analysis of companies, which was based on profitability, which can respond to the risks arising in business (Akatov, 2019) and (Polorecka, 2021). After identifying the profitability, we proceeded to assess the impact of the pandemic impact on the company's sales and their mutual year-onyear comparison. We performed all these tasks in the MS Excel program.

Profitability can be defined using several options, but in essence it is an expression of the company's profit after deducting all the costs incurred by it in carrying out its business activities. For the sake of expression, it is therefore necessary to find out the revenues of the companies, i.e. the value that was invoiced to them from the customers to whom they 
supplied the service (Kampova, 2018) and (Valaskova, 2020). After expressing sales, it is necessary to define costs and use the deduction method to determine the fair value of profit, which in a well-functioning company should be in positive numbers. If the value of the profit were in negative numbers, it would mean that it needs to be subsidized and cannot produce for its receivables (Soltes 2020).

\section{Results}

As we stated in the previous section, we were the first to express sales, these values are given in Table 1. As part of ensuring anonymity, we do not mention only the names 1-5 in the article.

Table 1. Expression of revenues of analyzed companies for the years 2015-2020.

\begin{tabular}{|c|c|c|c|c|c|}
\hline \multirow{2}{*}{ Year } & Company 1 & Company 2 & Company 3 & Company 4 & Company 5 \\
\cline { 2 - 6 } & Sales [€] & Sales [€] & Sales $[\boldsymbol{\epsilon}]$ & Sales $[\boldsymbol{\epsilon}]$ & Sales $[\boldsymbol{\epsilon}]$ \\
\hline 2015 & 180,136 & $5,005,009$ & $1,067,738$ & 501,904 & 157,377 \\
\hline 2016 & 187,976 & $4,374,003$ & $1,037,179$ & 840,944 & 155,509 \\
\hline 2017 & 287,167 & $3,862,132$ & $1,279,239$ & 587,218 & 204,020 \\
\hline 2018 & 186,316 & $3,826,181$ & $1,861,642$ & 699,344 & 168,889 \\
\hline 2019 & 172,283 & $3,034,947$ & $1,553,231$ & 665,053 & 184,476 \\
\hline 2020 & 176,149 & $3,940,054$ & $2,148,324$ & 583,939 & 71,639 \\
\hline
\end{tabular}

As we can see from the data in Table 1, despite the observance of pre-defined criteria, we see a difference in the revenues of companies, which can be caused by more lucrative orders for a higher financial amount. Table 2 shows the company's costs for providing the service according to the contractually agreed conditions.

Table 2. Expression of costs of analyzed companies for the years 2015-2020.

\begin{tabular}{|c|c|c|c|c|c|}
\hline \multirow{2}{*}{ Year } & Company 1 & Company 2 & Company 3 & Company 4 & Company 5 \\
\cline { 2 - 6 } & Costs $[\boldsymbol{\epsilon}]$ & Costs $[\boldsymbol{\epsilon}]$ & Costs $[\boldsymbol{\epsilon}]$ & Costs $[\boldsymbol{\epsilon}]$ & Costs $[\boldsymbol{\epsilon}]$ \\
\hline 2015 & 219,985 & $4,991,699$ & 928,536 & 453,206 & 159,995 \\
\hline 2016 & 203,921 & $4,352,188$ & 891,635 & 816,772 & 156,844 \\
\hline 2017 & 237,166 & $3,846,581$ & $1,052,296$ & 536,129 & 205,122 \\
\hline 2018 & 156,124 & $3,828,122$ & $1,576,671$ & 645,684 & 173,618 \\
\hline 2019 & 159,255 & $3,055,179$ & $1,423,962$ & 613,474 & 184,221 \\
\hline 2020 & 174,923 & $3,883,774$ & $1,906,399$ & 528,392 & 84,448 \\
\hline
\end{tabular}

From the results shown in Table 2, it is clear that the costs of the companies we evaluated to some extent copy the sales they had. More interestingly, it is not clear in 2019 and 2020 to see a rapid decline or increase in either indicator. However, as mentioned above, the basis is the profitability of the company, in which we based our opinion on the presented data and the results were presented in the graphic representation in Figure 1 for better clarity. 


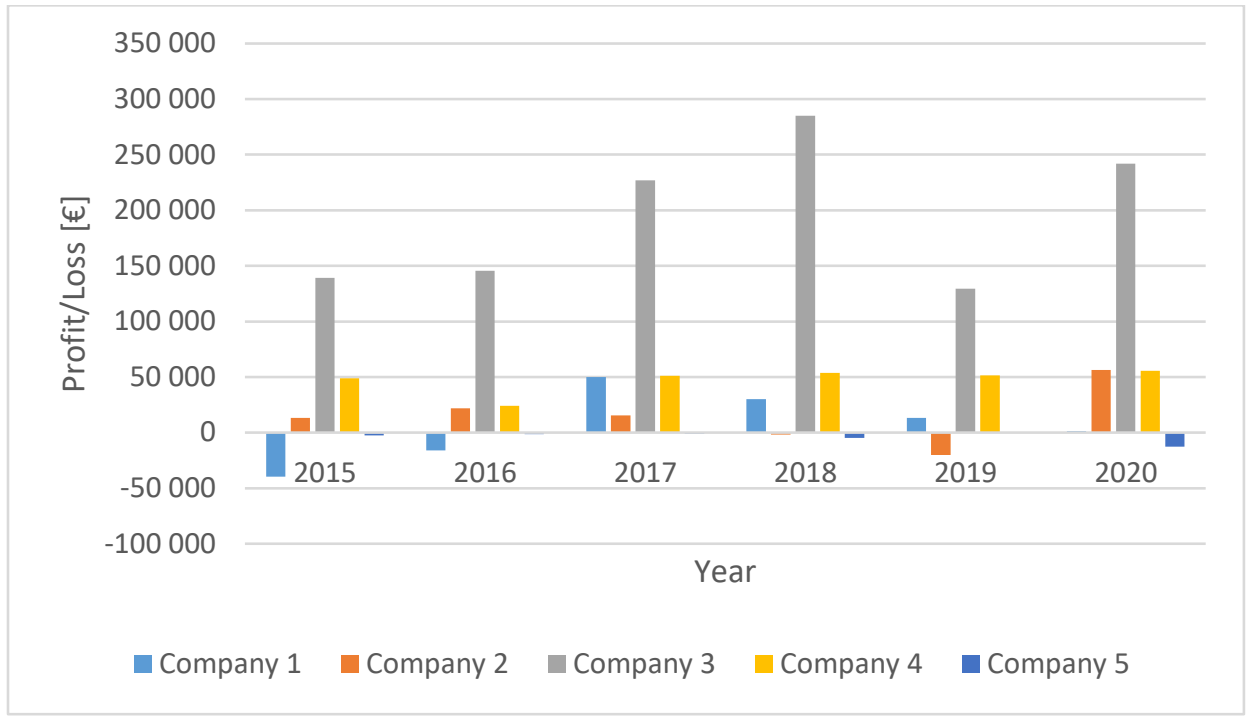

Figure 1. Expression of profit / loss of analyzed companies for the period 2015-2020.

As we can see from the results in Figure 1, with some exceptions, all companies are profitable in the long run, but except for Company 3, all were at a loss for at least one year. Despite the pandemic situation, companies' profits grew or remained at the long-term average. In one case, Company 3, we can see the direct impact of the pandemic in 2019 and the consequent increase in profits in 2020. The question remains how companies would be able to maintain profits in the future. For these needs, we created a forecast of the future situation for 2021 and 2022, assuming that we did not witness the rapid closure of the country as was the case in the first wave of the pandemic. The results of the profitability forecast can be seen in Table 3 .

Table 3. Expression of the profit / loss forecast of the analyzed companies for the periods $2021-2022$.

\begin{tabular}{|c|c|c|c|c|c|}
\hline \multirow{2}{*}{ Year } & Company 1 & Company 2 & Company 3 & Company 4 & Company 5 \\
\cline { 2 - 6 } & Profit/Loss [€] & Profit/Loss [€] & Profit/Loss [€] & Profit/Loss [€] & Profit/Loss [€] \\
\hline 2021 & 8,072 & 28,091 & 217,914 & 64,468 & $-10,176$ \\
\hline 2022 & 13,003 & 30,551 & 231,049 & 68,870 & $-11,852$ \\
\hline
\end{tabular}

As we can see from Table 3, almost all companies should record a growing profit in the coming period. Except for the last one, which increases in loss. This company should start thinking about changing the focus, or getting a bigger contract so that they are not forced to close their business.

\section{Discussion}

The results of the research are more favourable, as we have found that security companies are not largely affected by the COVID-19 pandemic. This fact is probably conditioned by the fact that even in times of land closure, hard lockdown and restriction of movement, members of the security services were needed, as the scope of their work is extensive (Soltes, 2021) and (Carr, 2021). 
In view of the global impact of the restrictions on society, it was necessary to involve a number of persons whose task was to control the entry of employees into the company premises, which was being carried out by security staff (Veljkovic, 2021). Their task is, among other things, to determine and maintain the economic profitability of the company from the point of view of security, i.e. the extent to which the funds spent on ensuring security are effective minutes (Kampova, 2019). By appropriate implementation of technical solutions, it is possible to set the quality of the security level using camera systems or access systems (Lovecek, 2017). It is these technical measures that represent the possibility of obtaining funding, as with the onset of the COVID-19 pandemic, the interest of companies to hold a license to operate a technical service that is authorized to install security systems has also increased. These have, in addition to the preventive point of view, also effective when they can replace the human factor and thus eliminate the probability of error (Soltes, 2016) and (Sventekova, 2011).

\section{Conclusion}

The aim of the paper was to analyse the profitability of companies operating in security in terms of adaptation to a global threat such as COVID-19. Using cost-benefit analysis, we identified and based on the results we can state that the pandemic situation of COVID-19 did not significantly affect the business in the field of security. Undoubtedly, the reason was also the need to ensure the security of entrances for employees who had to go to work, such as multinational manufacturing companies, critical infrastructure workers and the like.

Using the forecast of further development, we determined, assuming a stable level of measures against COVID-19, what profitability the analysed companies should have. It turned out that all but one company should prosper and increase profits in the future. In the future, it is possible to build on the results of research and analyse the veracity of the forecast as well as the impact of the increase in the number of requests for technical services on the profitability of companies.

\section{Acknowledgements}

This paper was supported by project VEGA 1/0173/21 and VEGA 1/0768/19.

\section{References}

1. Akatov, N., Mingaleva, Z., Klackova, I., Galieva, G., \& Shaidurova, N. (2019). Expert technology for risk management in the implementation of qrm in a high-tech industrial enterprise. Management Systems in Production Engineering, 27(4), 250-254.

2. Andrei, D., \& Hasler, M. (2020). Dynamic attention behavior under return predictability. Management Science, 66(7), 2906-2928.

3. Bockelmann, M., Nickel, P., \& Nachreiner, F. (2019). Ergonomics analysis of alarm systems and alarm management in process industries. Advances in Intelligent Systems and Computing, 822, 727-732.

4. Boros, M., Zvakova, Z., Soltes, V., \& Vel'as, A. (2021). What is the role of private intelligence in the Slovak Republic? Legal and practical aspects of private detective services. Security Journal.

5. Buganova, K., Hudakova, M., \& Maras, M. (2018). Market risk analysis in terms of impact on entrepreneurial activity of small and medium-sized enterprises in Slovakia. International Scientific Conference on Economic and Social Development, 402-410. 
6. Carr, S. C., Hopner, V., Hakim, M. A., Hodgetts, D. J., et al. (2021). Scaling the Security Staircase. Political Psychology, 42(4), 575-595.

7. Gruenbichler, R., Klucka, J., Haviernikova, K., \& Strelcova, S. (2021). Business performance management in small and medium-sized enterprises in the Slovak Republic: An integrated three-phase-framework for implementation. Journal of Competitiveness, 13(1), 42-58.

8. Kampova, K., \& Makka, K. (2018). Economic aspects of the risk impact on the fuel distribution enterprises. Transport Means - Proceedings of the International Conference, 231-235.

9. Kampova, K., Makka, K., \& Zvarikova, K. (2019). Cost benefit analysis within organization security management. International Scientific Conference Globalization and Its Socio- Economic Consequences - Sustainability in the Global-Knowledge Economy, 74.

10. Lovecek, T., Siser, A., \& Maris, L. (2017). Use case of waterwork physical protection system robustness evaluation as a part of slovak critical infrastructure. International Carnahan Conference on Security Technology.

11. Private Security Act - Law on the provision of services in the field of private security No. 473/2005. Online, available on: https://www.zakonypreludi.sk/zz/2005-473

12. Polorecka, M., Kubas, J., Danihelka, P., Petrlova, K., et all. (2021). Use of software on modeling hazardous substance release as a support tool for crisis management. Sustainability, 13(1).

13. Soltes, V., \& Stofkova, Z. (2016). Security as an aspect of the quality management in local self-government in age of globalization. International Scientific Conference on Globalization and its Socio-Economic Consequences.

14. Soltes, V., Kubas. J., \& Stofkova, Z. (2020). Possibilities of reducing regional disparities and supporting regional development. 35th International-BusinessInformation-Management-Association Conference (IBIMA), 6659-6666.

15. Soltes, V., Kubas, J., Velas, A., \& Michalik, D. (2021). Occupational safety of municipal police officers: Assessing the vulnerability and riskiness of police officers' work. International Journal of Environmental Research and Public Health, 18(11).

16. Sventekova, E., \& Dvorak, Z. (2011). Human activity as a risk in railway transport. International Conference on Transport Means.

17. Valaskova, K., Durana, P., Adamko, P., \& Jaros, J. (2020). Financial compass for slovak enterprises: modeling economic stability of agricultural entities. Journal of Risk and Financial Management, 13(5).

18. Veljkovic, D.R., Rancic, N.K., Mirkovic, M.R., Kulic, L.M., et all. (2021). Burnout among private security staff in serbia: A multicentic cross-sectional study. Frontiers in Public Health, 9. 